\title{
Effect of Goserlin Acetate and Oxidative Stress in Iraqi Women with Recurrenceof Endometriosis
}

\author{
Tamara Sami Naji ${ }^{*}$, Salwa H. N. Al- Rubae'i ${ }^{2}$ and Kisma M. Turki ${ }^{3}$ \\ ${ }^{I}$ PhD student at Department of Chemistry, College of Science, Al-Mustansiriya University, Baghdad, Iraq. \\ ${ }^{2}$ Professor in Biochemistry, Department of Chemistry, College of Science, Al-Mustansiriya University, \\ Baghdad, Iraq. \\ ${ }^{3}$ Professor in Biochemistry, College of Medicine, Baghdad University, Baghdad, Iraq.
}

\begin{abstract}
Although surgery is currently the treatment of choice for managing endometriosis, recurrence poses a formidable challenge. Goserlinacetateis one of the most widely used medical therapies of endometriosisto induce ovarian suppression. The aim of this study was to evaluate the effect of goserlin acetate treatment on the hormonal changes (Luteinizing Hormone (LH), Follicle Stimulating Hormones (FSH), Testosterone (Test.) and Estradiol $\left.\left(E_{2}\right)\right)$, antioxidant status $(A, E$, $\beta$-carotene and $C)$ vitamins, Coenzyme $Q_{10}\left(C_{0} Q_{10}\right)$, uric acid $(U A)$ and oxidative stress (MDA) in goserelintreated patients with endometriosis.Ninety women were participated in this study.Sixty women patients with endometriosiswere undergoing laparoscopy and treated with goserlin acetate included as patients group (G1), age range was between 25-46 years. Thirty healthy women were selected as the control group (G2) age range was between 23-45 years.Results revealed that there is the highly significant difference ( $P \leq 0.01$ ) between $G 1$ and $G 2$ groups in sera (Test., $E_{2}, \beta$-carotene, vitamin $C, C o Q_{10}$, UA and MDA) levels. The results showed a significant higher $(p<0.05) B M I, W / H$ and LH/FSHand lower level of vitamin $A$ in recurrent endometriosis in comparing with control group. Correlations studies indicated a significant correlation between Test. hormone and MDA levels in G1. The results of this study concluded that there is a significant and very effective role of goserlin acetate in alteration of the hormones changes and antioxidants status of women patients with endometriosis after the period of treatment. The relationship between the variables that increase in the Test. levels at the same time $E_{2}$ levels displayed highly significant depletion in G1 patients compared with G2.The effect of goserlin acetate by increasing the levels of oxidative stress and decreasing levels of antioxidant status. It is considered one of the most side effects of this treatment and prefers to choose other types of hormonal treatment to get a better result.
\end{abstract}

Keyword: Recurrence endometriosis, goserlin acetate, oxidative stress and antioxidant.

\section{Introduction}

Endometriosis is a benign, estrogen-dependent, chronic gynecological disorder characterized by the presence of endometrial tissue outside the uterus. Lesions are usually located on dependent surfaces in the pelvis and most often affect the ovaries and cul-de-sac. They can also be found in other areas such as the abdominal viscera, the lungs, and the urinary tract. Endometriosis affects (6-10\%) of women of reproductive age and is known to be associated with pelvic pain and infertility [1].Endometriosis can be a recurrent disease, both after cessation of medical suppressive treatment and after surgical treatment. Recurrences of endometriosis after surgery can be explained by incomplete surgery, persistence and growth of microscopic endometriosis, the development of new lesions, or a combination of these factors. However, it is not known whether temporary and repeated exposure to high $\mathrm{E}_{2}$ levels during controlled ovarian hyperstimulation ( $\mathrm{COH}$ ) for in vitrofertilization (IVF) contributes to the recurrence of endometriosis [2].Medical treatment of endometriosis typically involves hormonal manipulation of the menstrual cycle to create an amenorrheic state, thus producing an environment unfavorable to endometrial tissue. Danazol, progestational drugs, gestrinone, oral contraceptives, and gonadotropin-releasing hormone $(\mathrm{GnRH})$ agonists (GnRHa) are conventionally used medical agents. In addition, experimental medications, such as aromatase inhibitors, GnRH antagonists, pentoxifylline, tumor necrosis factor- $\alpha$ inhibitors, angiogenesis inhibitors, and matrix metalloproteinase inhibitors, hold the potential for greater efficacy and flexibility with fewer side effects[3].GnRHaare one of the most widely used medical therapies for endometriosis. These agents induce medical menopause by down-regulating hypothalamic-pituitary GnRH receptors, thus causing decreased gonadotropin secretion, suppression of ovulation and reduced serum estrogen levels. Several GnRHa used for the treatment of endometriosis include nafarelin, buserelin, histrelin, triptorelin, leuprolide and goserlin acetate[4].Goserelin acetate (trade name Zoladex) is a luteinizing hormone releasing hormone (LHRH) agonist ((LHRHa)). It is a synthetic analog of LHRH. LHRHainitially stimulate the release of LH, resulting in a transient elevation in serum estradiol in women. However, chronic administration can cause down-regulation of the LHRH receptors, thus inhibiting the secretion of LH and ultimately the sex hormones (androgen, estradiol).LHRHa reduce the ovarian secretion of estradiol and progesterone in women, leading to inhibition of 
estrogen-dependent cancers. Serum estradiol level is suppressed in women around 4 weeks after initiation of treatment. LHRHa are 50-100 times more potent than LHRH. In addition, they have a longer duration of action due to increased receptor affinity and greater biological stability [5].Estrogens have been shown to have in vitro antioxidant effects on membrane phospholipid peroxidation [6]. The antioxidant activity of estrogens is associated with the phenol structure of estradiol and its metabolites [7].Oxidative stress (OS) substances may have a contributive role in the pathogenesis of endometriosis through the activation of macrophages. These activated macrophages can aggravate oxidative stress conditions by the production of lipid peroxides and other by-products from reaction between apolipoproteins and peroxides [8].Vivian et al showed thatproduction of reactive oxygen species (ROS) by peritoneal fluid mononuclear cellswas increased in endometriosis[9].Oxidative damage occurs as a result of deficient antioxidant defensive mechanisms due to the effect of endogenous and exogenous factors. The aim of this study was to investigate the effect of goserlin acetate treatment on the hormonal changes, antioxidant status and oxidative stress (MDA) in goserelin acetatetreated patients with endometriosis and attempted to find the correlation between all these parameters with lipid peroxidation, given by MDA level's determination.

\section{Materials and Methods}

All chemical and reagents of analytical grade were purchased from Fluka unless indicated otherwise.

\subsection{Subjects}

Ninetywomen were participated in this study.Sixty womenpatients withendometriosis were undergoing laparoscopy and treated with goserlin acetate included as patients group (G1), age range was between25-46 years.The women patients were treated in Baghdad Teaching Hospital-Medical City and Kamal Al-Samarray Hospital, Baghdad, Iraq from January to July 2015.Thirty healthy women were selected as the control group (G2) age range was between 23-45 years. Thirty patients of women excluded, who were smoking and suffering from chronic or acute diseases such as hypertension, diabetes mellitus, diseases of the liver and kidney.

\subsection{Anthropometric Measurements}

Body mass index (BMI) was calculated as weight $(\mathrm{kg})$ divided by the height ${ }^{2}\left(\mathrm{~m}^{2}\right)$. Patients were taken as obese if their body mass index was 29.9 [10]. Waist:hip ratio (WHR) was calculated by dividing waist by hip measurements [11].

\subsection{Samples Analysis}

\subsubsection{Specimen collection}

Fasting blood samples $(10 \mathrm{~mL})$ were collected and placed into containing tubes during 2-5 days of the menstrual cycle. After centrifugation at $1500 \times \mathrm{g}$ for $10 \mathrm{~min}$. the sera were removed and retained for assay of the level of vitamin $\mathrm{C}$ and all the parameters, respectively. Serum samples were stored at $-80 \mathrm{C}^{\circ}$ until analysis.

\subsubsection{Laboratory assessments}

Serum concentration of (LH, FSH, Test.and $\mathrm{E}_{2}$ ) were measured by mini-VIDIS assay using kit supplied by Bio Merieux Sa-France. UAwas measured with an enzymatic colorimetric assay using a kit supplied by CromatestSpanish. $\mathrm{CoQ}_{10}$ was measured with a competitive inhibition enzyme immunoassay technique using a kit supplied by HCUSABIO-China. The vitamins (A, E \& $\beta$-carotene) were determined by a reverse-phase HPLC technique consisting of a Shimadzu-Japan binary solvent metering pump, a Rheodyne7125 injector with a $150 \mu \mathrm{L}$ sample loop, column $(25 \mathrm{~cm} \times 4.6 \mathrm{~mm}$ inner diameter $), 5 \mu \mathrm{m}$ partical size, injection volume $50 \mu \mathrm{L}$ and 10AV UV-Visible detector operatingat $\lambda_{\text {max }} 280 \mathrm{~nm}$ and $450 \mathrm{~nm}$ [12-13]. Vitamin C determination is based on the oxidation of ascorbic acid in serum by $\mathrm{Cu}^{2+}$ to form dehydroascorbic acid that react with the acidic 2,4dinitrophenyl hydrazine to form a red bis-hydrazone which is measured as (A $520 \mathrm{~nm}$ ) [14]. Malondialdehyde formed from the breakdown of poly unsaturated fatty acids serves as a convenient index of peroxidation reaction. The thiobarbituric acid method of [15], was used to measure MDA.

\subsection{Statistical analysis}

All data were expressed as mean \pm standard deviation (mean \pm SD). Statistical analysis was performed using LSD, considering $p<0.05$ as the lowest limit of significance. Statistical analysis was performed using a software program (SPSS 13 for Windows, USA). One-way analysis of variance (ANOVA) was used to compare means with least significant difference (LSD).

\section{Results}

As Table1 recurrence of endometriosis was visualized in 60 casesincluded 4-6 months (70.0\%) and 1-2 years (30.0\%) period of illness, among the cases, $(78.3 \%)$ were reported to have infertile status and $(21.6 \%)$ had healthy state,cases were more likely to have ovarian stimulation drug $(63.3 \%)$. Table2indicatesthe 
morphological and clinical characteristicsdistributed among twostudied groups. The majority of mean values (BMI, W/H ratio, $\mathrm{LH}, \mathrm{FSH}, \mathrm{LH} / \mathrm{FSH}$ ratio, Test., (UA and MDA as table3))wereestimated at the study of endometriotic patients with goserelin acetate treatment group (G1), $\left(28.03 \pm 5.65 \mathrm{Kg} / \mathrm{m}^{2}, \quad 0.87 \pm 0.17\right.$, $5.64 \pm 2.09 \mathrm{mIU} / \mathrm{mL}, 6.79 \pm 3.11 \mathrm{mIU} / \mathrm{mL}, 0.83 \pm 0.45,0.52 \pm 0.26 \mathrm{ng} / \mathrm{mL}, 378.71 \pm 27.78 \mu \mathrm{mol} / \mathrm{L}$ and $1.97 \pm 0.57$ $\mu \mathrm{mol} / \mathrm{L})$ respectively, while the lowest values estimate were recorded in normal interval with the control group (G2), $\quad\left(25.30 \pm 2.66 \mathrm{Kg} / \mathrm{m}^{2}, 0.79 \pm 0.08,4.96 \pm 2.40 \mathrm{mIU} / \mathrm{mL}, 6.60 \pm 1.84 \mathrm{mIU} / \mathrm{mL}, 0.75 \pm 0.19,0.27 \pm 0.11 \mathrm{ng} / \mathrm{mL}\right.$, $232.43 \pm 30.70 \mu \mathrm{mol} / \mathrm{L}$ and $0.65 \pm 0.12 \mu \mathrm{mol} / \mathrm{L}$ ) respectively.Table 3 displayed the lowest mean values of antioxidant vitamins (A, E, $\beta$-carotene, $\mathrm{C}$ and $\left.\mathrm{CoQ}_{10}\right)$ and $\left(\mathrm{E}_{2}\right.$ as table2) levels were estimated in $\mathrm{G} 1,(0.03 \pm 0.01 \mathrm{mg} / \mathrm{dL}, \quad 0.86 \pm 0.26 \quad \mathrm{mg} / \mathrm{dL}, \quad 0.09 \pm 0.01 \mathrm{mg} / \mathrm{dL}, \quad 1.12 \pm 0.41 \mathrm{mg} / \mathrm{dL}, \quad 33.04 \pm 9.83 \mathrm{ng} / \mathrm{mLand}$ $33.94 \pm 5.82 \mathrm{pg} / \mathrm{mL})$ respectively, while the majority values estimate were in the $\mathrm{G} 2(0.04 \pm 0.0 \mathrm{mg} / \mathrm{dL}$, $0.98 \pm 0.29 \mathrm{mg} / \mathrm{dL}, \quad 0.17 \pm 0.05 \mathrm{mg} / \mathrm{dL}, \quad 1.68 \pm 0.20 \mathrm{mg} / \mathrm{dL} \quad$ and $\quad 42.31 \pm 3.64 \mathrm{ng} / \mathrm{mL} \quad$ and $51.18 \pm 14.44 \mathrm{pg} / \mathrm{mL}$ )respectively. The results from thisstudy revealed that (Test., UA and MDA) levels were highly significant increased ( $\mathrm{P} \square 0.01$ ), while a (BMI, W/H and LH/FSH) levels were significant increased $(\mathrm{p}<0.05)$. Vitamins $\left(\beta\right.$-carotene, $\mathrm{C}$ and $\left.\mathrm{CoQ}_{10}\right)$ and $\mathrm{E}_{2}$ showed a highly significant decreased ( $\square$ $\square .001)$.However,a significant decreased $(\mathrm{p}<0.05)$ was noticed in vitamin Alevel.LH and FSHlevels were non significantincreased $(p>0.05)$, whereasanon significantdecreased( $p>0.05)$ of vitamin E levelin G1 compared with G2.Table 4shows the correlation between oxidative stress index (represented by MDA level) and concentration of hormones, antioxidant vitamins and uric acid in recurrent endometriotic patients. There was negative correlation between the levels of $\mathrm{LH} / \mathrm{FSH}$ ratio, $\mathrm{E}_{2}$, Vitamins $\mathrm{A}, \mathrm{E}, \mathrm{CoQ}_{10}$ and UA. Whereasapositive correlation was observed between LH, FSH, $\beta$-carotene, vitamin C and Test. with increased in MDA levels.

Table1Characteristics of the recurrent endometriotic patients in this study.

\begin{tabular}{|l|l|}
\hline Parameter & Distribution among total subjects (n=60) \\
\hline Duration of disease & \\
(4-6)months & $42(70.0 \%)$ \\
(1-2)years & $18(30.0 \%)$ \\
\hline Marital status & \\
Married & $1(1.6 \%)$ \\
Unmarried & $59(98.3 \%)$ \\
\hline Case of reproduction & \\
Infertile women & $47(78.3 \%)$ \\
Healthy women & $13(21.6 \%)$ \\
\hline Ovarian stimulation drug & \\
Yes (Puregon+Tamoxifen) & $38(63.3 \%)$ \\
No & $22(36.6 \%)$ \\
\hline
\end{tabular}

Table2.The morphological andclinical characteristics measurements in sera of the studied groups.

\begin{tabular}{|l|l|l|l|}
\hline Parameters & $\begin{array}{l}\text { G1 (patients) } \\
(\mathrm{N}=60) \\
\text { Mean } \pm \text { SD }\end{array}$ & $\begin{array}{l}\text { G2 (control) } \\
\text { (N=30) } \\
\text { Mean } \pm \text { SD }\end{array}$ & P-Value \\
\hline Age (years) & $32.86 \pm 6.17$ & $31.96 \pm 5.42$ & NS \\
\hline BMI $\left(\mathrm{Kg} / \mathrm{m}^{2}\right)$ & $28.03 \pm 5.65$ & $25.30 \pm 2.66$ & $0.013^{*}$ \\
\hline Waist/Hip ratio & $0.87 \pm 0.17$ & $0.79 \pm 0.08$ & $0.015^{*}$ \\
\hline LH $(\mathrm{mIU} / \mathrm{mL})$ & $5.64 \pm 2.09$ & $4.96 \pm 2.40$ & $\mathrm{NS}$ \\
\hline FSH $(\mathrm{mIU} / \mathrm{mL})$ & $6.79 \pm 3.11$ & $6.60 \pm 1.84$ & $\mathrm{NS}$ \\
\hline LH/FSH & $0.83 \pm 0.45$ & $0.75 \pm 0.19$ & $0.003^{*}$ \\
\hline Test. $(\mathrm{ng} / \mathrm{mL})$ & $0.52 \pm 0.26$ & $0.27 \pm 0.11$ & $0.001^{* *}$ \\
\hline $\mathrm{E}_{2}(\mathrm{pg} / \mathrm{mL})$ & $33.94 \pm 5.82$ & $51.18 \pm 14.44$ & $0.001^{* *}$ \\
\hline
\end{tabular}

*NS: non significant at $\mathrm{p}>0.05,{ }^{*}$ significant at $\mathrm{p}<0.05$ and $* *$ highly Significant at $\mathrm{p} \leq 0.01$ level.

Table3. Serum levels of antioxidant status and MDA in G1 and G2 groups.

\begin{tabular}{|l|l|l|l|}
\hline Parameters & $\begin{array}{l}\text { G1 (patients) } \\
(\mathrm{N}=60) \\
\text { Mean } \pm \text { SD }\end{array}$ & $\begin{array}{l}\text { G2 (control) } \\
\text { N=30) } \\
\text { Mean } \pm \text { SD }\end{array}$ & P-Value \\
\hline Vit. A $(\mathrm{mg} / \mathrm{dL})$ & $0.03 \pm 0.01$ & $0.04 \pm 0.01$ & $0.006^{*}$ \\
\hline Vit. E $(\mathrm{mg} / \mathrm{dL})$ & $0.86 \pm 0.26$ & $0.98 \pm 0.29$ & NS \\
\hline$\beta$-caroten $(\mathrm{mg} / \mathrm{dL})$ & $0.09 \pm 0.01$ & $0.17 \pm 0.05$ & $0.001^{* *}$ \\
\hline Vit. C $(\mathrm{mg} / \mathrm{dL})$ & $1.12 \pm 0.41$ & $1.68 \pm 0.20$ & $0.001^{* *}$ \\
\hline $\mathrm{CoQ}_{10}(\mathrm{ng} / \mathrm{mL})$ & $33.04 \pm 9.83$ & $42.31 \pm 3.64$ & $0.001^{* *}$ \\
\hline $\mathrm{UA}(\mu \mathrm{mol} / \mathrm{L})$ & $378.71 \pm 27.78$ & $232.43 \pm 30.70$ & $0.001^{* *}$ \\
\hline MDA $(\mu \mathrm{mol} / \mathrm{L})$ & $1.97 \pm 0.57$ & $0.65 \pm 0.12$ & $0.001^{* *}$ \\
\hline
\end{tabular}

*NS: non significant at $\mathrm{p}>0.05,{ }^{*}$ significant at $\mathrm{p}<0.05$ and $* *$ highly Significant at $\mathrm{p} \leq 0.01$ level. 
Table4.Correlation coefficients and the significant levels of different serum chemical components in patients with recurrent endometriosis.

\begin{tabular}{|l|l|l|l|l|l|}
\hline Component vs. MDA & Slope & Intercept & $\mathrm{R}^{2}$ & $\mathrm{r}$ & P-Value \\
\hline LH $(\mathrm{mIU} / \mathrm{mL})$ & 0.026 & 1.824 & 0.009 & 0.096 & 0.612 \\
\hline FSH $(\mathrm{mIU} / \mathrm{mL})$ & 0.002 & 1.954 & 0.000 & 0.016 & 0.934 \\
\hline LH/FSH & -0.026 & 1.998 & 0.000 & -0.021 & 0.913 \\
\hline Test $(\mathrm{ng} / \mathrm{mL})$ & 0.816 & 1.311 & 0.160 & $0.400^{*}$ & 0.020 \\
\hline $\mathrm{E}_{2}(\mathrm{pg} / \mathrm{mL})$ & -0.004 & 2.212 & 0.014 & -0.119 & 0.532 \\
\hline Vit. A $(\mathrm{mg} / \mathrm{dL})$ & -2.883 & 2.071 & 0.006 & -0.083 & 0.662 \\
\hline Vit. E $(\mathrm{mg} / \mathrm{dL})$ & -0.103 & 2.062 & 0.002 & -0.047 & 0.805 \\
\hline$\beta$-caroten $(\mathrm{mg} / \mathrm{dL})$ & 4.427 & 1.549 & 0.009 & 0.099 & 0.602 \\
\hline Vit. C $(\mathrm{mg} / \mathrm{dL})$ & 0.095 & 1.866 & 0.004 & 0.068 & 0.720 \\
\hline CoQ10 $(\mathrm{ng} / \mathrm{mL})$ & -0.008 & 2.267 & 0.018 & -0.134 & 0.497 \\
\hline UA $(\mu \mathrm{mol} / \mathrm{L})$ & -0.004 & 3.584 & 0.042 & -0.205 & 0.277 \\
\hline
\end{tabular}

Correlation is non significant at $\mathrm{p}>0.05, *$ Correlation is significant at $\mathrm{p}<0.05$ level.

\section{Discussion}

Endometriosis is a common disease, defined as the presence of endometrial-like tissue outside the uterus, which induces a chronic, inflammatory reaction. While some women with endometriosis can experience painful symptoms and/or infertility, others have no symptoms at all. Susceptibility to endometriosis depends on a complex interaction of immunologic, genetic and hormonal factors [16].Theoretically, the recurrent lesions might originate from either residual lesions or de novo cells coming through retrograde bleeding. For the former assumption, several studies demonstrate that the recurrence risk increases if the lesions are not completely removed at the initial surgery and they tend to arise on the same location [17].Six months of GnRHa therapy immediately following surgery reduces the rate of symptom recurrence of endometriosis, and increases the length of time before symptoms recur. It is also more effective in managing endometriosis-related pain after surgery than using oral contraceptives in the same way [18]. In this study BMI was elevated significantly in group of treatment with goserelin as compared with control group, and this agreement with Alonso et al who found to have higher BMI and correlated with higher testosterone and lower total estradiol [19]. [20]Shown that BMI increases during treatment with GnRHa as a side effect. The body fat distribution, simply measured by the waist to hip girth, is supposedly a more important factor in predicting the risk of related diseases than the grade of obesity as determined by the BMI. [21]Revealed that greater waist to hip ratio is associated with risk of endometriosis. This finding supports the highly significant increase of $\mathrm{W} / \mathrm{H}$ ratio in $\mathrm{G} 1$. Conventional medical treatment of endometriosis focuses on reducing estrogenstimulation, managing pain and preserving fertility. Hormone therapy is commonlyutilized because endometrial tissue responds to hormone stimulation.Estrogen has been shown to increase aberrantendometrial lesions, while progesterone and androgens maydecrease implant size [22]. Studies of the effects of testosterone derivative used in the treatment of endometriosis, menorrhagia, and endometrial hyperplasia, can contribute to the discussion of the effect of androgens on endometrial growth. In one study, women with endometrial hyperplasia received goserlin acetate and after this treatment, $82.8 \%$ showed a reversal of hyperplasia as assessed by clinical and histological examination. Furthermore, endometrial atrophy was detected in $65.8 \%$, and amenorrhea in $90 \%$. These findings support the biological capacity of goserlin acetate, a testosterone derivative, to reverse endometrial growth [23].In the current study, it is found that an increased in Test levels in G2, due to the potential occurrence of testosterone surges on repeat injection of the goserelin acetate has also been investigated by [24].Conversely, the highly significant decrease of estrogen in G2 compared with G1. Goserelinacetateis medicines that work by causing a temporary menopause. They are modified forms of GnRH that bind to receptors in the pituitary but have a longer half-life than native GnRH and thereby in down-regulation of the pituitary-ovarian axis and hyperestrogenism, The treatment causes the ovaries to stop producing estrogen, which causes the endometriosis implants to shrink [25].Murphy et al whofound increased oxidation of low-density lipoprotein and increased concentrations of oxidized low-density lipoproteins in the peritoneal fluid in patients with pelvic endometriosis. Oxidative modification of these molecules involves peroxidation of the lipid component, which leads to release of aldehydes, such as malondialdeyde[26]. When oxidative stress was thought to be incriminated in endometriosis pathophysiology, antioxidants like vitamins (A, E, $\beta$-carotene, $C$ and $C o Q_{10}$ ) were evaluated.Our result were in agreement with Szczepanskaet alwho reported that women with endometriosis had significantly lower levels of antioxidants than women without endometriosis, and significantly higher levels of lipid peroxides [27].A study by [28] reported that serum $\mathrm{CoQ}_{10}$ levels were higher among postmenopausal than among premenopausal women, suggesting that circulating steroid hormone or gonadotropin concentrations may influence plasma levels of $\mathrm{CoQ}_{10}$. For this reason, it is possible that we propose in this study that the effect of goserlin acetate was evident in the endometriotic patients that migratory rise Test hormone and lower level of estradiol that affects the level of $\mathrm{CoQ}_{10}$. Indeed, uric acid is the most abundant aqueous antioxidant, accounting for up to $60 \%$ of plasma antioxidative capacity. The antioxidative effect of uric acid is evidenced by its ability to directly scavenge free 
radicals or to form stable complexes with transition-metal ions, such as iron, thereby preventing ascorbate oxidation and lipid peroxidation [29].Jackson et al found that there was a positive association between oxidative stress and endometriosis [30].In the current study, it is found the correlation between MDA and different variables measured in goserlin acetate-treated patients. These correlations were represented by a linear regression where the slope represents the direct effect of MDA on each variables level in patients, while the intercept represents the accumulative effect of other factors. A positive significant correlation between MDA and testosterone hormone in recurrent endometriotic patients. A negative correlation between $\mathrm{E}_{2}$ and MDA. Our findings suggest that ovarian $\mathrm{E}_{2}$ production may play an important antioxidant role, an inverse correlation between $\mathrm{E}_{2}$ and lipid peroxide production with aging have been reported [31]. Whereas anegativecorrelation between MDA level and vitamins (A, E, UA and $\mathrm{CoQ}_{10}$ ), suggesting a deficiency in these vitamins or its consumption as an antioxidant secondary to the excessive production of free radicals.

\section{Conclusion}

From all the aforementioned observations it can be concludedthat there is a significant and very effective role of goserlin acetate in alteration of the hormones changes and antioxidants status of women patients with endometriosis after the period of treatment.The results of this study showed the relationship between the variables that increase in the Test.levelsat the same time $E_{2}$ levels displayed highly significant depletion in G1 patients compared with G2. In addition, the result of this study describes the effect of goserlin acetate by increasing the levels of oxidative stress and the low levels of antioxidant status.It is considered one of the most side effects of this treatment and prefers to choose other types of hormonal treatment to get a better result.

\section{References}

[1]. AshokAgarwal, Anamar Aponte-Mellado, Beena J Premkumar, Amani Shaman, Sajal Gupta. The effects of oxidative stress on female reproduction: a review. Reproductive Biology and Endocrinology, 2012; 10(49):1-31.

[2]. ThomasD'Hooghe, ChristelMeuleman, Sophie Debrock. Is the endometriosis recurrence rate increased after ovarian hyperstimulation?. Fertility and Sterility, 2006; 86(2):283-290.

[3]. Sebihaozkan, William murk, Aydin. Endometriosis and Infertility Epidemiology and Evidence-based Treatments, New York Academy of Sciences, 2008; 1127:92-100.

[4]. Dan Wang, Yuhuan Liu, Jie Han, et al. Puerarin Suppresses Invasion and Vascularization of Endometriosis Tissue Stimulated by 17b-Estradiol. PLoS ONE, 2011; 6(9):1-6.

[5]. Engel JB, Schally AV, Engel JB, et al. Drug Insight: clinical use of agonists and antagonists of luteinizing-hormonereleasing hormone. Nat ClinPractEndocrinolMetab, 2007; 3(2):157-67.

[6]. Massafra C, Gioia D, Felice C De, Picciolini E, Leo V De, Bonifazi MBernabei A. Effects of estrogens and androgens on erythrocyte antioxidant superoxide dismutase, catalase and glutathione peroxidase activities during the menstrual cycle. Journal of Endocrinology 2000;167:447-452.

[7]. Joachim G, LiehrDeodutta, Roy Pro. Oxidant and antioxidant effects of estrogen. Methods in molecular biology, 1999; 108:425-435.

[8]. Lambrinoudaki IV, Augoulea A, Christodoulakos GE, et al. Measurable serum markers of oxidative stress response in women with endometriosis. FertilSteril, 2009; 91:46-50.

[9]. Vivian F. Do Amarala, S.P. Bydlowskib, et al. Lipid peroxidation in the peritoneal fluid of infertile women with peritoneal endometriosis. European Journal of Obstetrics \& Gynecology and Reproductive Biology, 2005; 119:72-75.

[10]. Denise R. Ferrier. Biochemistry Lippincotts illustrated reviews. $6^{\text {th }}$ ed, chapter 26, 2014:349-350.

[11]. Mohamadin AM, Habib FA, Elahi TF. Serum paraxonase 1 activity and oxidant/antioxidant status in saudi women with polycystic ovary syndrome. Pathophysiology 2010;17:189-196.

[12]. George E. Nichoalds. Simultaneous Determination of Retinol and $\alpha$-Tocopherol in Serum or Plasma by Liquid Chromatography. CLIN CHEM 1983;29:4708-712.

[13]. WIlliam J Driskell, Mark M Bashor, Jane W Neese. Beta-Carotene Determined in Serum by Liquid Chromatography with an Internal Standard. CLIN CHEM 1983;29:61042-1044.

[14]. McComic DB. Vitamins. In: Tietz NW, editor. Textbook of clinical chemistry. Philadelphia, PA:WB Saunders Company 1986:932-33, 960-62.

[15]. Buege JA, Aust SD. Microsomal lipid peroxidation methods Enzymol 1978;52:302-310.

[16]. Dunselman G.A.J., Vermeulen N., Becker C., et al. ESHRE guideline: management of women with endometriosis. Human Reproduction, 2014; 0(0):1-13.

[17]. GurkanBozdag. Recurrence of endometriosis: risk factors, mechanisms and biomarkers. Womens Health, 2015; 11(5):693699.

[18]. Maha AK Al-Azzawy. Goserelin acetate for recurrent endometriosis IRAQI J MED SCI,2012; 10(1):22-26.

[19]. Alonso A, Sipilä S, Kujala U M, Kaprio J, Rantanen T. Genetic influences on adult body mass index followed over 29 years and their effects on late-life mobility: a study of twin sisters. J Epidemiol Community Health, 2009; 63:651-658.

[20]. ZohrehKaramizadeh, AnisAmirhakimi, GholamhosseinAmirhakimi. Effect of Pubertal Suppression on Linear Growth and Body Mass Index; a Two-Year Follow-Up in Girls with Genetic Short Stature and Rapidly Progressive Puberty, Iran J Pediatr, 2014; 24(3):293-299.

[21]. Hediger M, Hartnett H, Louis G. Association of endometriosis with body size and figure. FertilSteril, 2005, 84:1366-74.

[22]. Chris D. Meletis, NieskeZabriskie. Natural Approaches to Relieving Endometriosis. ALTERNATIVE \& COMPLEMENTARY THERAPIES, 2005; 185-190.

[23]. Lina Al-Imari, Wendy L. Wolfman.The Safety of Testosterone Therapy in Women. J ObstetGynaecol Can, 2012; 34(9):859-865. 
[24]. Sharifi R, Browneller R, the Leuprolide Study Group. Serum testosterone suppression and potential for agonistic stimulation during chronic treatment with monthly and 3-month depot formulations of leuprolide acetate for advanced prostate cancer. J Urol, 2002; 168:1001-1004.

[25]. Dunselman GA, Vermeulen N, Becker C, et al. ESHRE guideline: management of women with endometriosis. Hum Reprod, 2014; 29:400.

[26]. Murphy AA, Palinski W, Rankin S, Morales AJ, Parthasarathy S. Macrophage scavenger receptor(s) and oxidatively modified proteins in endometriosis. FertilSteril, 1998; 69:1085-94.

[27]. Szczepanska M, Kozlik J, Skrzypczak J, Mikolajczyk M. Oxidative stress may be a piece in the endometriosis puzzle. FertilSteril 2003; 79:1288-1293.

[28]. Parloop A. Bhatt Akshita B. Bhatt. COENZYME Q10 SUPPLEMENT IN BREAST CANCER: THE NUTRIENT ON HORIZON. Kadakia International Journal of Research in Multidiscipline, 2014; 1(1):150-158.

[29]. MladenBoban, DarkoModun. Uric Acid and Antioxidant Effects of Wine. Croat Med J, 2010; 51:16-22.

[30]. Jackson L W, Schisterman EF, Dey-Rao R, Browne R, Armstrong D. Oxidative stress and endometriosis, Human Reproduction, 2005; 20(7):2014-2020.

[31]. Sagara Y. The climacteric: ageing of ovary and objective evaluation of the climacteric symptoms. Nippon SankaFujinkaGakkaiZasshi, 1989; 41:1039-1044. 